\title{
Destino de la Poesía Ecuatoriana de Nuestro Tiempo
}

TABLANDO en términos de afinidad de sentimiento y vida II cronológica, está bien poner los nombres de Arturo Borja y de Noboa Caamaño 1 al lado de los de Humberto Fierro y Medardo Angel Silva. Pero en el mapa - bastante reducido por cierto- de la poesía ecuatoriana, cada uno de ellos se halla situado en diferente latitud espiritual y a distinta altura. Borja está en el río de la emoción fácil y transparente. Noboa Caamaño se resiste a entrar en la selva dantesca, donde guiña sus ojos la locura. Fierro y Silva siguen caminos más altos: el uno a su cita con la muerte y el otro a su desposorio con la soledad.

Estos cuatro poetas ecuatorianos, rezagados de las filas románticas, buscaron los maravillosos específicos del Modernismo para prolongar su vida; pero su esfuerzo fué inútil. Murieron de sus heridas ya viejas, causadas en las profundas batallas del Romanticismo. Medardo Angel Silva fué quien más resistió al asalto tremendo, valiéndose de las armas musicales que Darío había forjado en Francia. Como éstas no detuvieran al mortal enemigo, el poeta. recurrió a los bálsamos frescos y olorosos de Juan Ramón Jiménez, el de la época de los jardines. Todo fué en vano. En el primer descuido, la herida romántica se le agravó, llevándole al suicidio. 2

¿Por qué cuando soñaba mis sueños infantiles, en la cuna, a la sombra de las gasas sutiles, de un ángulo del cuarto no salió una serpiente que, al ceñit sus anillos a mi cuello inocente con la flexible gracia de una mujer querida, 


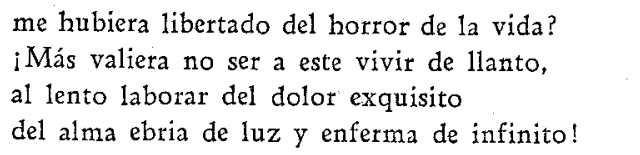

(Silva: "Suspiria de profundis")

Humberto Fierro había leído muchos libros. Se deleitaba con el vocablo, era un fino cazador del matiz, conocía la entrada secreta de la cueva mitológica. Oscilaba entre el candor y la sabiduría. Mas, aunque llevaba siempre consigo el antídoto de la cultura, el veneno romántico de la soledad irremediable terminó con su vida. 3

La nueva generación poética del Ecuador no olvidó la lección de sus precursores. Trató de fabricar, desde el primer momento, la coraza indispensable para resistir a la acometida romántica. " $\mathrm{E} 1$ que de acero su alma no reviste - nunca está bien en medio de los vivos", había dicho Noboa Caamaño. Era necesario, de este modo, buscar los hondos metales. Formar un equipo de resistencia y abandonar los caminos descubiertos. Así fué apareciendo un nuevo territorio espiritual y se sintió, por primera vez, la solidaridad, el espíritu de grupo, la belleza de la tierra, la magia de las cosas que habían sido antes menospreciadas.

El equipo rehabilitador del valor humano de la poesía en el Ecuador se presentó hace una veintena de años; mas, no ha cesado de tener significación actual, debido a que nuevos elementos han engrosado sus filas en los últimos tiempos. Los poetas más representativos de esa reacción contra la derrota romántica y vital son, indudablemente, Gonzalo Escudero, Miguel Angel León, Jorge Reyes, Abel Romeo Castillo, Alejandro Carrión y G. Humberto Mata. 4

Escudero comenzó por cantar a la piedra, al cataclismo, a las fuerzas cósmicas. Llevado un pocø por la embriaguez verbal, se perdió entre los dólmenes, las vorágines, los huracanes. Pero con esos inmensos materiales, iba reconstruyendo el paisaje americano, desordenado y ciclópeo. Su evocación de la fuerza natural es positiva y su vigoroso lenguaje hace entrever una futura derivación hacia la poesía épica.

Miguel Angel León, quien acaba de morir lamentablemente en el umbral de la madurez, sumó su voz de metal y de altura a la de los poetas nuevos, con su "Canto al Chimborazo" y sus poemas elementales sobre el fuego, el agua, el viento, la tierra. El Chimborazo 
se presenta a los ojos del poeta como "la carpa más alta del vivac de los Andes, - donde acampó la raza del indio". León, maestro de provincia y amigo de los trabajadores manuales, mantuvo hasta el instante postrero el fulgor de su optimismo, un poco sepultado bajo la volcánica ceniza andina.

El postmodernismo ecuatoriano constituye el mayor intento de realización de una poesía propia en el asunto y en el espíritu. Aparecieron los "poemas indios", "los poemas de la tierra" y se trató de exaltar al "hombre del Ecuador". Alguien hizo desfilar, en una' serie de cuadros poéticos, la feria o mercado popular, la cosecha de cebada, el levantamiento indígena. Era una poesía de insurgencia y de vigor, después de la interminable y refinada agonía modernista. La poesía se adelantaba, así, a la novela de protesta social y preparaba el terreno para su advenimiento.

"Hay tardes en las que uno desearía - embarcarse y partir sin rumbo cierto", suspiraba Noboa Caamaño en su tiempo. Muchos años después, se oye la voz de Jorge Reyes: "Frente a la vida guardo la actitud del chalán frente a los potros chícaros; - he roto ese retrato de fraile que es mi infancia - y soy como deben ser los hombres". Todo el proceso espiritual de un país, se halla entre estas dos actitudes. En 1910, las continuas incursiones de los peruanos en los territorios del Ecuador, obligaron al Gobierno del general Alfaro a preparar militarmente a todos los ciudadanos y a organizar la resistencia contra el infatigable invasor. Arturo Borja aprovechaba los momentos que le dejaba libre la instrucción en los cuarteles para escribir su "Epístola a don Ernesto de Noboa y Caamaño", en que se lamentaba de la vida militar de Quito. Fierro, Noboa y Borja desertaron frecuentemente del servicio, refugiándose en haciendas o pueblecitos de los alrededores para cambiar impresiones sobre sus lecturas o para leer sus propios poemas. Noboa Caamaño sabía de memoria "Les Complaintes" de Laforgue. Fierro aparecía con lujosas ediciones de libros raros y repetía frecuentemente par delicatesse - jai perdue ma vie. 5

El anhelo de los poetas de esa época era la evasión de la realidad, hostil y mezquina. La amenaza de guerra exterior, las contiendas civiles, los prejuicios sociales y'religiosos, la limitación económica, hacían más agudo su pesimismo para el que no encontraban otra solución que la escapada a países extranjeros, o la muerte, que es también una especie de fuga clandestina. "Muda nodriza, llave de 
nuestros cautiverios - oh Tú, que a nuestro lado vas con paso de sombra!", le imploraba Silva a la muerte. Toda esa generación desventurada capituló ante el dolor y cayó vencida. Fué la patrulla de descubierta en las avanzadas de la cultura. La generación que vino después miró con amor la realidad circundante y encontró la belleza del paisaje ecuatoriano. Consideró a Quito como un "arrabal del cielo" — ciudad construída en el "tejado del mundo"-, e inició el "nuevo descubrimiento de Guayaquil". Se dió cuenta de que el pesimismo de la generación romántico-modernista amenazaba invadir integramente el espíritu nacional y comprendió su misión y su destino: restaurar la confianza en el hombre ecuatoriano, hallar el significado de la tierra, difundir su mensaje de rebeldía y de esperanza.

Indiscutiblemente, Jorge Reyes es uno de los iniciadores de esta nueva actitud poética. En sus dos libros de poenas publicados hasta hoy, se manifiesta un criollismo auténtico. La vida de los zaguanes, las charlas callejeras, las tempestades ecuatoriales, las leyendas que corren de boca en boca, las costumbres, el Quito "de sayal y guitarra" le deben felices interpretaciones. La pipa de madera que Jorge Reyes ha mordido durante tantos años con frío coraje, debe ser venerada por los nuevos poetas, pues en ella se han vuelto humo todos los sollozos, dejando solamente visible la persistente y encendida brasa.

Buena parte ds su juventud vivió Abel Romeo Castillo en Madrid. En la biblioteca, en los pasos de sombra y de sol o en el Parque del Retiro, fué madurando su amor por la tierra ecuatoriana. Sacudió el polvo de los Archivos de Indias para componer un nutrido libro de investigaciones históricas acerca de Guayaquil, su ciudad de origen. 6 Ese libro es un homenaje monumental al puerto ilustre y activo que ha dado al Ecuador gobernantes y poetas y que fué en siglos pasados el astillero mayor del Océano que recorrían los galeones españoles. Mas, no se contentó Abel Romeo Castillo con ofrecer al puerto natal su paciente trabajo de historia, sino que quiso darle también su contribución poética. Penetró, con ese objeto, en el folklore y recorrió todas sus calles y meditó bajo sus palmeras. El mismo amor que García Lorca tenía por su Granada, tiene Abel Romeo Castillo por su Guayaquil. Escribió el romance del incendio de las casas de madera del arrabal, el romance de los viejos tranvías tirados por caballejos - o, en frase costeña, de "las gón- 
dolas de mulas del malecón"-, el romance del conspirador enamorado: todo en lenguaje directo de giro popular, hecho para fijarse sin dificultad en la memoria. Su poesía cumple de esta manera una función exaltadora del espíritu ecuatoriano.

Alejandro Carrión, nacido en Loja en 1915, llamó a su primer libro de poesía $L u z$ del nuevo paisaje. Después de las derrotas pasadas, venían por fin hombres jóvenes con ojos limpios, dispuestos a la reconstrucción de la alegría. Carrión canta al buen año, al trabajo agrícola y envía su mensaje de esperanza a los hombres sencillos que caen en España defendiendo su tierra y su libertad.

Sobre la angustia de los hombres fué madurando el trigo...

Debió haber nacido la alegría

Debió haber nacido la sontisa sobre el campo dorado.

$$
\text { (Carrión: "Canción de la cosecha") }
$$

Esta es la misma actitud espiritual de G. Humberto Mata, Llerena, Sacotto Arias y todos los poetas de la nueva generación. Mas, la poesía de Mata tiene una virtud de indignación contagiosa. Tal vez no sea del gusto de todos su elocuencia torrencial. Es posible también que se escape a algunos su original vocabulario. No es menos eficaz, por eso, su grito atropellado y numeroso. La amenaza precisa que se transparenta en la voz de G. Humberto Mata, se vuelve canto esperanzado en José Alfredo Llerena, Augusto Sacotto Arias, Ignacio Lasso:

El río se apagó, pero en cambio se oían los pasos de los soldados, los pasos no querian apagarse con las tempestades, los llanos no querían agotarse con los pasos, los pasos no querían apagarse con los llanos...

Dios sigue detrás de los pasos.

Dios va siguiendo a los soldados.

$$
\text { (Llerena: "Agonía y paisaje del caballo") }
$$

Vamos a ser nuevos como esta aurora que empieza. sencillos e ingenuos tal este clarín que malogra un delicado y magnífico tisú en la primera tienda del silencio.

$$
\text { (Lasso: "Escafandra") }
$$


Un día

no seremos

ni este silencio en marcha ni este pulso aún dócil

sino una campanada de veinte años.

Nuestra canción

ha de desentornar sus párpados de pólvora.

Se ha de crispar el aire.

Que lo sepan desde hoy las vidrieras urbanas!

(Sacotto Arias: "El porvenir del humo")

En su último cuaderno poético, Sismo, Sacotto Arias incluye una "exhortación a la muerte"; pero ésta no es una muerte sin combate. Bien al contrario... No se crea, sin embargo, que esta actitud afirmativa y esforzada perjudique a la calidad del-trabajo poético que viene realizando la nueva generación. Nunca el material idiomático había llegado en la poesía ecuatoriana a la transparencia expresiva, a la vibración espiritual, al puro matiz y al candor de imágenes que alcanza en ciertos poemas de Lasso o de Sacotto Arias. Habla este último con frecuencia de las "magnolias enfermeras", del "atlas sencillo de la alondra", del "epitafio del jacinto", o también:

de la gran revista azul del alba que desde el primer día se ha coleccionado en la biblioteca de los ángeles.

(Sacotto Arias: "Encuesta de los puntos cardinales")

Al libro Escafandra de Ignacio Lasso pertenecen estas imágenes sutiles y acertadas, de factura perfecta, que, cuando fueron traducidas al francés para una revista de Bruselas, quedaron como dentro de su verdadero clima:

Trepaban por la sombra surtidores de música, yedras de una sustancia más feliz que el silencio.

Una luz tamizada por membranas de agua, erigía delgadas columnas inefables.

Arrugados heliotropos de aire devengaban menudo polen de ausencias. $Y$ de no poder regresar la mirada se endurecía el tiempo, fosilizando domesticadas faunas de recuerdos. 
Salí en tu busca por todos los colores y por todas las latitudes del perfume; hacia el fondo, en la marea de esas músicas húmedas donde las valvas nacaradas de las lunas ofrecen alegres dehiscencias de besos.

(Lasso: "Mireille")

Una moza que pasa, un instante reclina su mirada más dulce encima de mi canto, $y$ se va presurosa sintiendo que la noche desciende paso a paso la grada en caracol del huracán, hacia el río, que de flaco y enfermo, el pobre ya no puede levantar ni una piedra.

De una simple migaja de tristeza, le ha nacido al crepúsculo tanta golondrina, que no sabe cómo educar el vuelo del ángelus, ni distribuir la luz de las estrellas.

\section{(Lasso: "Agro")}

La orientación espiritual de un país sigue su movimiento semejante al de las mareas. La cultura avanza en sucesivos oleajes encontrados, en flujo y reflujo incesantes. Pero cada ola, al retirarse, deja su escritura en la arena, sus despojos de peces, sus plumas de gaviota y sus misteriosos restos submarinos. La generación romántico-modernista dejó en la playa ecuatoriana algo más: una huella de sangre y un jeroglífico de muerte. La nueva ola -o mejor, la generación íltima- quiere borrar esas siniestras señales. De todas partes del horizonte acuden frescos refuerzos para la tarea. Se puede afirmar que la poesía en el Ecuador de nuestro tiempo es un fenómeno unánime, nacido de un estado de espíritu nacional. Mientras la novela se ha circunscrito a cada región - hasta el punto de que hay una "novela de la costa" y una "novela de la sierra", un "grupo de Guayaquil" y un "grupo de Quito" - la poesía se ha vuelto un lazo común, un esfuerzo integrador del país y de toda una juventud, que tiene representantes en la capital, en Guayaquil, en Loja, en Cuenca, en Ibarra. 7 
Hay, así, una definida poesía ecuatoriana, caracterizada por su identidad de destino. Es cierto que, a veces, se encuentran supervivencias de la actitud espiritual pasada; pero esas no son sino las islas que hay en todo mar, y no llegan a constituir un archipiélago. Alfredo Gangotena es la mayor de esas islas. Nadie ha explorado todavía su territorio de sombra, sus profundidades abisales, su fauna y su flora de misterio. Gangotena ha llamado acertadamente a su último libro Tempestad secreta. En efecto, su poesía se obscurece de pronto, se ilumina de relámpagos internos, castiga con sus azotes líquidos, sacude y destruye los terrenos deleznables, dejando en pie solamente el acantilado ceñudo y sin edad.

"Hemos vivido en familia con las tormentas, - algo más, las hemos domesticado", dijo cierta vez Ignacio Lasso. Gangotena no conoció esa prueba tormentosa, pues estuvo ausente o retirado del afán colectivo. Vivió muchos años en París y escribió sus primeros libros en francés, entre los cuales está esa Orografía deliciosa e inolvidable. Su catolicismo y su natural refinamiento, le han impedido la actitud de protesta. Le cher Gangó - como le llama Supervielle- está a merced de la tempestad y sus fantasmas. Esperamos que las bellas construcciones de su isla no sean destruídas por alguna próxima acumulación de nubes.

La poesía ecuatoriana de nuestro tiempo tiene, así, como misión esencial domesticar la tempestad. Cuando se clausure la época tenebrosa en que vivimos, será posible establecer un balance justo de su significación y sus resultados. Por el momento, el trabajo poético crece sin cesar: Jorge I. Guerrero, Pedro Jorge Vera, Manuel Agustín Aguirre, Atanasio Viteri y otros más, suman su esfuerzo y su voz a la construcción futura. 8 Hasta los novelistas como Enrique Gil Gilbert y Gallegos Lara, en la pausa de dos relatos de vital colorido, escriben poemas de alto e inconfundible clima humano. Porque la poesía ecuatoriana cumple a toda costa con su destino, que es parte del destino universal en estos turbios años: exaltar la rebeldía y la esperanza de los hombres.

Jorge Carrera Andrade 


\section{NOTAS}

1 Arturo Borja, muerto a los veintiún años, no publicó ningún libro. Un lustro después de su muerte, sus amigos editaron La flauta de ónix, entre cuyos poemas insertaron, por error, uno de Luis Rosado Vega, el poeta mexicano de Vaso espiritual. Ernesto Noboa Caamaño murió en 1928, a los 36 años de edad, dejando un solo libro de poemas: La tomanza de las horas, editado por la Biblioteca Nacional de Quito. Antes que la influencia baudelairiana señalada por Benjamín Carrión en su Indice de la poesía ecuatoriana contemporánea, se pueden notar en su poesía las inconfundibles huellas de Verlaine y de Samain.

2 Medardo Angel Silva es todo el Modernismo en el Ecuador. A pesar de su corta vida, escribió muchísimos poemas que no se han coleccionado después. En 1926, Gonzalo Zaldumbide hizo una edición de los mejores poemas de Silva, precedidos de un interesante estudio crítico.

3 Humberto Fierro publicó en 1920 su libro poético El laúd en el valle, con dibujos de su propia mano. Un nuevo manuscrito de poemas, Velada palatina, entregó para su publicación a la Editorial Artes Gráficas de Quito, hacia el año de 1928. No se sabe la razón por la que esa Editorial no lo ha publicado todavía. Dejó también inéditos, al morir, otro libro de poesía, Ancora, y un libro de prosas sin título.

4 Todos ellos nacieron en los primeros años de este siglo, exceptuando Cartión, que es el más joven del grupo.

5 Estos versos pertenecen a la "Chanson de la Tour plus Haute" de Rimbaud.

6 E1 título es Gobetnadores de Guayaquil en los siglos XVII y XVIII (Prólogo de Rafael Altamira). Se publicó en 1931, en Madrid, ciudad donde Castillo vivía en esa época, participando activamente en los movimientos de la Federación de Estudiantes de la Universidad de San Carlos, en los bravos dias en que ésta se proclamó "cantón republicano".

7 En efecto, G. Humberto Mata es de Cuenca, Alejandro Carrión y Manuel Agustín Aguirre son de Loja, Abel Romeo Castillo y Pedro Jorge Vera, de Guayaquil. Miguel Angel León y Jorge I. Guarrero nacieron en Riobamba. Escudero, Lasso, Gangotena y otros más son quiteños. Augusto Sacotto Arias tiene como tierra natal la provincia del Cañar. Humberto Vacas, el autor de "Canto a lo Obscuro", nació en Ibarra. Hay también poetas de otras varias localidades geográficas.

8 No han publicado libros todavía, pero revelan un seguro temperamento poético: José Joaquín Silva, actualmente en Chile, Carlos M. Espinosa, Pincay Coronel y Hugo Alemán, en constante evolución espiritual. Antonio Montalvo merece sitio aparte por la exquisitez de su lirismo, y a pesar de que últimamente se ha dedicado al comentario critico, se puede decir que se halla realizando una especie de "poesía de la crítica". 


\section{BIBLIOGRAFIA POETICA}

GonZAlo Escudero. Hélices de hutacán y de sol. Madrid, 1934.

MigUel ANGEL LEÓN. Labios sonámbulos. Riobamba, 1921.

JORGE REYES. Treinta poemas de mi tietra. Quito, 1930.

. Quito, arrabal del cielo. Quito, 1930.

ANGEL ROMEO CASTILlO. Nuevo descubtimiento de Guayaquil. Guayaquil, 1935.

AlEJANDRo Carrión. Luz del nuevo paisaje. Quito, 1935.

- Corazones atravesados de un tatido. Cuenca, 1934.

José AlFredo LleRENA. Agonía y paisaje del caballo. Quito, 1934.

IGNACIO LAsso. Escafandta. Quito, 1934.

AUGUSto SACOTTO ARIAs. Velorio del albañil. Quito, 1939.

Sismo. Tokijo, 1940.

AlfRedo GANGOTENA. Tempestad secreta. Quito, 1940.

PEDRO JORGE VERA. Nuevo itinerario. Quito, 1935.

. Romances madtugadotes. Guayaquil, 1931.

Manuel Agustín Aguirre. Poemas automáticos. Guayaquil, 1931.

- Llamada de los proletarios. Guayaquil, 1935.

ATANASIO VITERI. Marino azat. Quito, 1940. 